\title{
Phytochemical Constituents of Three Species of Marine Macro- Algae from Sitio Usadda, Pangutaran, Sulu, Philippines
}

\author{
Maribelle Tambihul Hanani \\ Department of Aquaculture, Mindanao State University, Sulu, Philippines
}

Email address:

mycabelle@gmail.com

\section{To cite this article:}

Maribelle Tambihul Hanani. Phytochemical Constituents of Three Species of Marine Macro- Algae from Sitio Usadda, Pangutaran, Sulu, Philippines. American Journal of Applied Chemistry. Vol. 9, No. 4, 2021, pp. 97-101.

doi: $10.11648 /$ j.ajac.20210904.11

Received: May 24, 2021; Accepted: June 21, 2021; Published: July 13, 2021

\begin{abstract}
Seaweeds are a rich source of highly potential bioactive compounds in the pharmaceutical industry. To date, many chemically unique compounds of marine origin with various biological activities have been isolated and some of them are under investigation and to develop new pharmaceuticals. The phytochemical screening will be limited to the determination of alkaloids, flavonoids, saponins, tannins and terpenoids using two organic solvents such as ethanol and methanol. The result of the phytochemical test proves that there is a difference in the capacity of different solvents to extract active compounds. In methanol extracts tannins and terpenoids are present in Ulva reticulate in moderate amount. Terpenoids are slightly present in Sargassum cristaefolium and terpenoids and saponins are slightly present in Halymenia durvillei. In methanol extracts Ulva reticulata contains coumarins and saponins in moderate amount and terpenoids is only slightly present. Also, the methanol extract of Sargassum cristaefolium and Halymenia durvillei, contain terpenoids in moderate amount. It can be deduced from the screening test that terpenoids is the dominant constituents present in the three algal samples. Both ethanol and methanol seaweed extracts showed that alkaloids, flavonoids and xanthoprotein were absent in the three seaweed extracts of $U$. reticulata, $S$. cristaefolium and $H$. durvillei. An absence of alkaloid in $U$. reticulata in present study is due to effect of the geographical location and seasons of collection. Differences can be attributed to solubility of active component in different solvents used. Methods of extraction were possible sources of variation for chemical composition and extracted for bioactivity reaction. Indeed, there is no doubt that more terpenoids identified from marine algae will become available and will be used in food industry and will be utilized as source of natural antioxidant and clinical drugs that will play a significant role in human disease treatment in the future.
\end{abstract}

Keywords: Phytochemical Screening, Macro-algae, Seaweeds, Bioactive, Algal Extraction

\section{Introduction}

Sulu is one of the seaweeds suppliers in western Mindanao. Species like Sargassum, Ulva and Halymenia spp. are just flaking in the shoreline for no one knows their benefits. Seaweeds are the sources of phytochemicals namely: agar agar, carrageenan and algin. They are also used as feedstuff for animal consumption [1]. Seaweeds are a rich source of highly potential bioactive compounds in the pharmaceutical industry. To date, many chemically unique compounds of marine origin with various biological activities have been isolated and some of them are under investigation and are being used to develop new pharmaceuticals [26]. Generally, the study aims to investigate the phytochemical constituents of selected species of seaweeds. Specifically; to find out the presence of active chemical constituents in the selected algae using two solvents and to compare solvents (ethanol and methanol) that exhibit intense phytochemical constituents as it provides basic information about the medicinal importance of the algal extract in the search for more effective biomedical compounds for drug formulation, biological activity is the initial step. Thus, results generated from this study could provide information for students, researchers and faculty members who are interested into this field of 
endeavor. Algal samples will be limited to three species, a representative of the three major groups of algae, i.e. Chlorophyceae. Phaeophyceae and Rhodophycea. The phytochemical screening will be limited to the determination of alkaloids, flavonoids, saponins, tannins and terpenoids using two organic solvents such as ethanol and methanol.

\subsection{Phytochemical}

Phytochemicals are non-nutritive bioactive plant substance. Seaweeds are source of biologically active phytochemicals, which include carotenoids, phycobilins, fatty acids, polysaccharides, vitamins, sterols, tocopherol and phycocyanins among others. Total extraction of material carried out by any polar solvents such as acetone, aqueous methanol (80\%) and aqueous ethanol, and then re-extraction with hexane, chloroform and ethyl acetate also lead to successive extraction of terpenoids and sterols [5].

Natural products can be mainly divided into three groups such as primary metabolites, secondary metabolites and high molecular weight polymeric materials [14]. Primary metabolites includes nucleic acids, amino acids, sugars occur in all cells and play central role in metabolism and reproduction of the cells. High molecular weight polymeric materials such as cellulose, lignins and proteins take part in cellular structure. Natural product term refers to any naturally occurring compounds but in most cases mean secondary metabolite [20].

Phytochemical-rich foods should clearly form part of healthy balanced diet. However, the human body has number of physiological, biochemical and enzymatic processes by which it can combat oxidative stress outside of dietary intake.

While above finding casts doubt on the benefit of increasing polyphenolic consumption from the perspective of reducing oxidative stress, it must be noted that such compounds may have other physiological effects. Previous studies in animal models and cell culture have suggested that seaweed phytochemicals have potential to inhibit the progression of carcinoma formation [2].

\subsection{Qualitative Phytochemical Analysis}

Qualitative phytochemical analysis can be performed by means of preliminary analysis through test tube methods, for the following: alkaloids, coumarins, flavonoids, saponins, tannins, terpenoids and xanthoprotein.

Alkaloids have many pharmacological activities including antihypertensive effects, antiarrhythmic effect (quinidine, spareien), anti-malarial activity (quinine), and anticancer actions (dimeric indoles, vincristine, and vinblastine). Some alkaloids have stimulant property as caffeine and nicotine, morphine are used as the analgesic and quinine as the antimalarial drug [27]. Alkaloids have wide range of pharmacological activities including antimalarial, Antiasthma and anticancer [16].

Coumarin is a phytochemical with vanilla-like flavor. Coumarin increases blood flow in veins; has anti-fungicidal and anti-tumor activities; and decreases capillary permeability. It is used in the treatment of asthma [17].

Flavonoids have been stated to possess many useful properties, containing anti-inflammatory activity, enzyme inhibition, antimicrobial activity, estrogenic activity, antiallergic activity, vascular activity and cytotoxic antitumor activities but best describe property of almost group of flavonoids is their capacity to act as powerful antioxidant, which can protect the human body from free radical and reactive oxygen species. [24]. Flavonoids constitute a wide range of substances that play important role in protecting biological systems against the harmful effects of oxidative processes on macro-molecules, such as carbohydrates, proteins, lipids and DNA [4].

Saponins are a subclass of terpenoids, the largest class of plant extracts. The amphipathic nature of saponins gives them activity as surfactants with potential ability to interact with cell membrane components, such as cholesterol and phospholipids, possibly making saponins useful for development of cosmetics and drugs. [18] Saponins have also been used as adjuvants in development of vaccines, [23]. Saponins has antitumor and anti-mutagenic activities and can lower risk of human cancers, by preventing cancer cells limit their growth and viability. When ingested by humans, it seems to help the immune system and protects against viruses and bacteria [13].

Tannins are anti-nutritional compound that are said to have antimicrobial activity. Tannins has several health benefits have been recognized for the intake of tannins and some epidemiological associations with the decreased frequency of chronic diseases have been established [22] and as antiinflammatory, antiseptic, antioxidant and haemostatic pharmaceuticals [8]. In medicine, especially Asian natural healing, the tannin-containing plant extracts are used as astringents, against diarrhea, as diuretics, against stomach and duodenal tumors [7]. Terpenoids are generally alicyclic lipid-soluble compounds and isomerism is common. It has anti-inflammatory and antioxidant activities [15]. Terpenoids contain additional functional groups, usually containing oxygen. [6] Terpenoids are the largest class of plant secondary metabolites, representing about $60 \%$ of known natural products. [12]. Many terpenoids have substantial pharmacological bioactivity and are therefore of interest to medicinal chemists [3].

Xanthoprotein is qualitative test for presence of protein. It is a yellow acid substance formed by the action of hot nitric acid on albuminous or protein matter and is changed to a deep orange-yellow color by the addition of ammonia [13].

\section{Materials and Methods}

\subsection{Collection of Algal Sample}

Three species of marine macro representing the three major groups i.e. Chlorophyceae, Phaeophyceae and rhodophyceae will be collected from the intertidal zone of Sitio Usadda, Pangutaran, Sulu, Philippines. The collected 
algal samples had been cleaned of epiphytes and extraneous matter and necrotic parts been removed.

\subsection{Preparation of Extracts for Phytochemical Screening}

Extraction of the algal samples was done following the method of Seenivasan (2012) [21] with slight modification. Powdered samples were soaked in organic solvents (ethanol and methanol) for 72 hours at 1: $4 \mathrm{w} / \mathrm{v}$ concentrations. After which they were filtered with filter paper and the filtrates were used in the screening test for the presence of phytochemicals.

\subsection{Screening for the Presence of Phytochemicals}

Algal extracts were subjected to various qualitative chemical tests to screen for the presence of biomolecules by using the standard qualitative procedures as described in literature Trease and Evans [25].

Test for Alkaloids: $1 \mathrm{ml}$ of $1 \% \mathrm{HCl}$ was added to the $3 \mathrm{ml}$ of algal extract in a test tube and was treated with few drops of Meyer's reagent. A creamy white precipitate indicated the presence of alkaloids.

Test for Coumarins: $1 \mathrm{ml}$ algal extract was mixed with few drops of $\mathrm{NaOH}$ and $1 \mathrm{ml}$ alcohol was added. Formation of yellow color indicated the presence of coumarins.

Test for Flavonoids: A few drops of $1 \% \mathrm{NH}_{3}$ solution was added to the $2 \mathrm{ml}$ of extract in a test tube. A yellow coloration was observed for the presence of flavonoids.

Test for Saponins: $5 \mathrm{ml}$ of extract was shaken vigorously to obtain a stable persistent froth. The frothing was then mixed with 3 drops of olive oil and observed for the formation of emulsion, which indicated the presence of saponins.

Test for Tannins: To $0.5 \mathrm{ml}$ of extract solution, $1 \mathrm{ml}$ of distilled water and 1-2 drops of ferric chloride solution were added and observed for brownish green or a blue black coloration.

Test for Terpenoids: $5 \mathrm{ml}$ of extract was mixed with $2 \mathrm{ml}$ of $\mathrm{CHCl}_{3}$ in a test tube. $3 \mathrm{ml}$ of concentrated $\mathrm{H}_{2} \mathrm{SO}_{4}$ was carefully added along the wall of the test tube to form a layer. An interface with a reddish brown coloration was confirmed the presence of terpenoids

Test for Xanthoprotein: $1 \mathrm{ml}$ algal extract was mixed with few drops of ammonia. Formation of red color indicated the presence of xantho- proteins

\section{Result and Discussion}

Result of phytochemical test proved that there was difference in the capacity of different solvents to extract active compounds.

Both ethanol and methanol seaweed extracts showed that alkaloids, flavonoids and xanthoprotein were absent in the three seaweed extracts of $U$. reticulata, $S$. cristaefolium and H. durvillei. In contrast, the study of Varghese (2010) [26] showed that $U$. reticulata contains alkaloids. Absence of alkaloid in $U$. reticulata in present study maybe due to effect of the geographical location and seasons of collection. Differences can be attributed to solubility of active component in different solvents [9]. Methods of extraction were possible sources of variation for chemical composition and bioactivity of extracts [10]. Figure 1 showed the reaction of screening using methanol extraction and figures 2 and 3, the reaction of extraction using ethanol

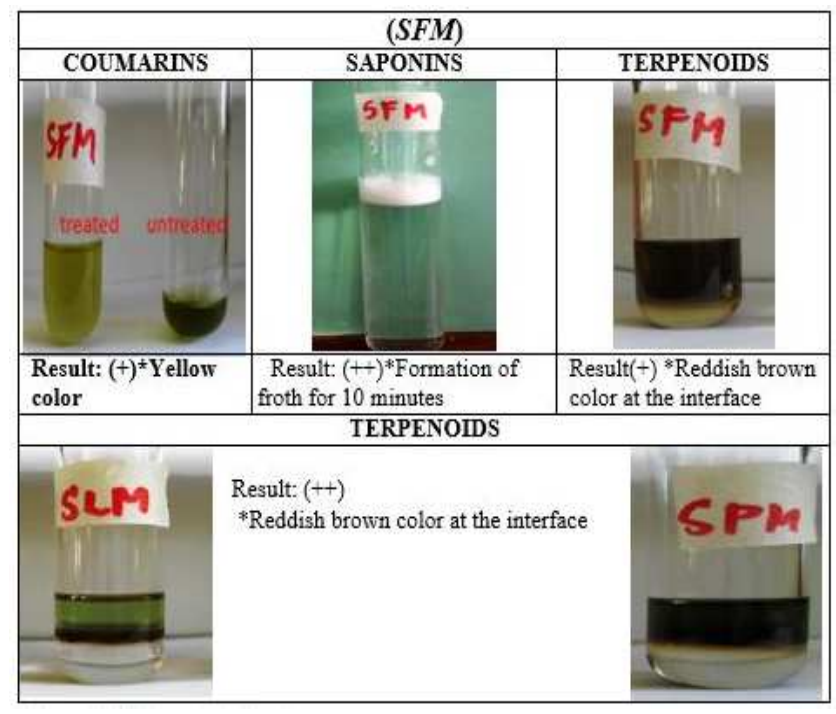

Figure 1. Methanol Extracts.
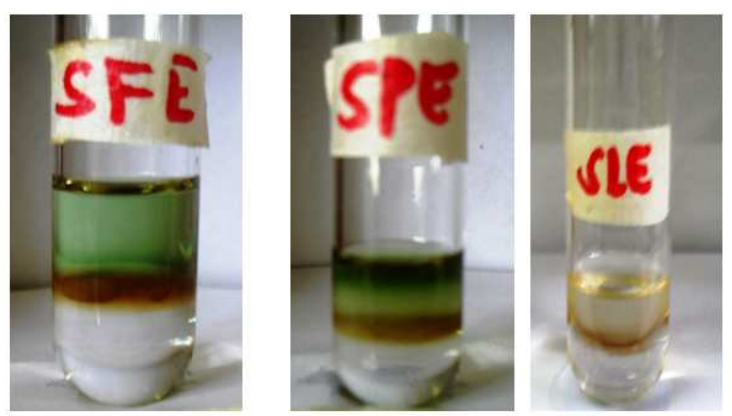

The presence of terpenoids in ethanol extract from Ulva reticulata, S. cristaefolium and $H$. durvillei

Figure 2. Ethanol Extracts.

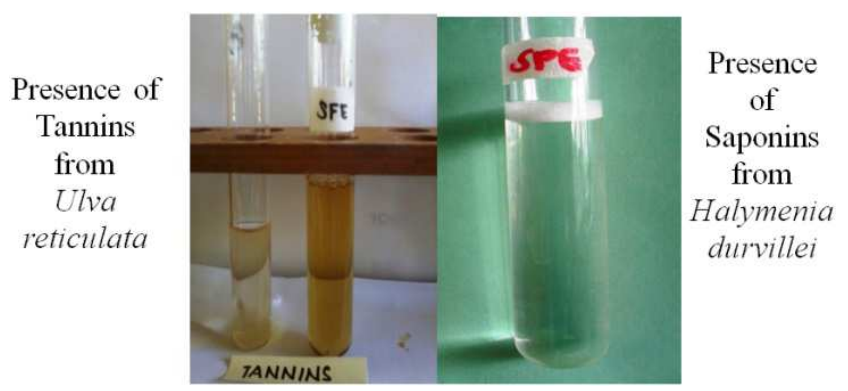

Figure 3. Ethanol Extracts.

Phytochemical screening test of the three marine algae namely Ulva reticulata, Sargassum cristaefolium, and Halymenia durvillei showed the presence of saponins, tannins, and terpenoids in ethanol extract and coumarins, saponins and terpenoids in methanol extract (Table 1). 
Table 1. Phytochemical constituents of ethanol and methanol extract in three marine macro-Algae.

\begin{tabular}{|c|c|c|c|c|c|c|c|}
\hline \multirow{2}{*}{ Taxon } & \multicolumn{7}{|c|}{ Phytochemicals } \\
\hline & Alkaloids & Cou ma rins & Flavonoids & Saponins & Tan nins & Terpenoids & Xan thoprotein \\
\hline \multicolumn{8}{|l|}{ Ethanol } \\
\hline Ulva reticulata & - & - & - & - & ++ & ++ & - \\
\hline Sargassum cristaefolium & - & - & - & - & - & + & - \\
\hline Halymenia durvillei & - & - & - & + & - & + & - \\
\hline \multicolumn{8}{|l|}{ Methanol } \\
\hline Ulva reticulata & - & ++ & - & ++ & - & + & - \\
\hline Sargassum cristaefolium & - & - & - & - & - & ++ & - \\
\hline Halymenia durvillei & - & - & - & - & - & ++ & - \\
\hline
\end{tabular}

The result of the phytochemical test proves that there is a difference in the capacity of different solvents to extract active compounds. In methanol extracts tannins and terpenoids are present in Ulva reticulate in moderate amount. Terpenoids are slightly present in Sargassum cristaefolium and terpenoids and saponins are slightly present in Halymenia durvillei. In methanol extracts Ulva reticulata contains coumarins and saponins in moderate amount and terpenoids is only slightly present. Also, the methanol extract of Sargassum cristaefolium and Halymenia durvillei, contain terpenoids in moderate amount. It can be deduced from the screening test that terpenoids is the dominant constituents present in the three algal samples.

Terpenoids are important as an additive in the food industry and as a pharmaceutical agent in biomedicine. Terpenoids have found application in food industry. The act as antioxidant agent. Antioxidants significantly extend the shelf-life of foods containing oxidizable lipids such as vegetable oils, animal fats, flavorings, spices, nuts, processed meats and snack products [11]. Terpenoids are pharmaceutical agents. They act as agent in the formulation of topical drugs. They are percutaneous permeation enhancer increasing the solubility of drugs in skin lipid, disruption of lipid/protein organization and/or extraction of skin micro constituents that are responsible for maintenance of barrier status. Hence, they appear to offer great promise for use in transdermal formulations. [19].

\section{Conclusion}

Indeed, there is no doubt that more terpenoids identified from marine algae will become available and will be used in food industry and will be utilized as source of natural antioxidant and clinical drugs that will play a significant role in human disease treatment. Hence, the seaweeds screened in this study possess phytochemicals, antioxidants, and antimicrobial potentials, which may be considered for future applications in medicine, cosmetics and pharmaceutical industry as a matter of fact, seaweeds is a food for human consumption.

\section{References}

[1] ANANTHARAMAN P., K. MANIVANNAN, G. KARTHIKAIDEVI and G. THIRUMARAN. 2009. Element composition of certain seaweeds from Gulf of Mannar Marine Biosphere Reserve, Southeast Coast of India. World Journal of Dairy and Food Sciences 4: 1-46.

[2] APOSTOLIDIS, E., and C. M. LEE. 2010. In-vitro potential of Ascophyllum nodosum phenolic antioxidant-mediated alpha-glucosidase and alpha-amylase inhibition. Journal Food Science 75 (3): 97-102.

[3] ASHOUR, MOHAMED; WINK, MICHAEL; GERSHENZON, JONATHAN (2010). "Biochemistry of Terpenoids: Monoterpenes, Sesquiterpenes and Diterpenes". Biochemistry of Plant Secondary Metabolism. pp. 258-303. 55.

[4] ATMANI D, NASSIMA C, DINA A, MERIEM B, NADJET D, HANIA B, 2009. Flavonoids in Human Health: From Structure to Biological Activity Current Nutrition \& Food Science, 5: 225-237.

[5] BHAT, S. V., B. A. NAGASAMPAGI, and M. SIVAKUMAR. 2005. Chemistry of Natural Products. Narosa Publishing House, India.

[6] CHEMISTRY, INTERNATIONAL UNION OF PURE AND APPLIED. IUPAC Compendium of Chemical Terminology. IUPAC. doi: 10.1351 /goldbook. T06279.

[7] DE BRUYNE T, PIETERS L, DEELSTRA H, VLIETINCK A. 1999 Condensed vegetables tannins: biodiversity in structure and biological activities. Biochemical System Ecology; 27: 445-59.

[8] DOLARA P, LUCERI C, DE FILIPPO C, FEMIA AP, GIOVANNELLI L, CARDERNI G, CECCHINI C, SILVI S, ORPIANESI C, CRESCI 2005. A. Red wine polyphenols influence carcinogenesis, intestinal microflora, oxidative damage and gene expression profiles of colonic mucosa in F344 rats. Mutation Research,; 591: 237-46.

[9] EKPO M. A. and P. C. ETIM. 2009. Antimicrobial activity of ethanolic and aqueous extracts of Sida acuta on microorganisms from skin infections. Journal of Medicinal Plants Research 3: 621- 624. 
[10] FELIX M. T. 1982. Medicinal Microbiology. Churchill Livingstone: London, U. K. 848 pp.

[11] FINLEY, J. W. AND P. GIVEN JR. Technological necessity of antioxidants in the food industry. 1986. Food and chemical toxicology. Vol 2, Issues 10-11, pp. 997-1255.

[12] FIRN R (2010). Nature's Chemicals. Oxford: Biology.

[13] GEORGE, T. W., E. PATERSON, S. WAROONPHAN, M. H. GORDON and J. A. LOVEGROVE. 2012. Effects of chronic consumption of fruit and vegetable puree-based drinks on vasodilation, plasma oxidative stability and antioxidant status. Journal on Human Nutrition and Dietetics 25 (5): 477-487.

[14] HANSON, J. R. 2003. Natural products the secondary metabolites. The Royal Society of Chemistry 1-27. Cambridge, UK.

[15] HOUGHTON, P. J., A. Y. MENSAH, N. IESSA, and L. Y. HONG. 2003. Terpenoids in Buddleja: relevance to chemosystematics, chemical ecology and biological activity. Phytochemistry 64: 385-393.

[16] KITTAKOOP, P., C. MAHIDOL, and S. RUCHIRAWAT. 2014. Alkaloids as important scaffolds in therapeutic drugs for the treatments of cancer, tuberculosis, and smoking cessation. Current Top Medical Chemistry 14 (2): 239.

[17] LIU, H. 2011. Extraction and Isolation of Compounds from Herbal Medicines. In: J. Willow and H. Liu (eds.) Traditional Herbal Medicine Research Methods. John Wiley and Sons, Inc.

[18] LORENT, JOSEPH H.; QUETIN-LECLERCQ, JOËLLE; MINGEOT-LECLERCQ, MARIE-PAULE (2014). "The amphiphilic nature of saponins and their effects on artificial and biological membranes and potential consequences for red blood and cancer cells". Organic and Bio-molecular Chemistry. Royal Society of Chemistry. 12 (44).
[19] SAPRA BHARTI, SUBHEET JAIN, A. K TIWARY. 2008.

[20] Percutaneous permeation enhancement by terpenes: Mechanistic view. The AAPS Journal, Vol. 10, issue 1 pp 120-1.

[21] SARKER, S. D. and L. NAHAR. 2005. Hyphenated techniques. In: S. D. Sasker, Z. Latif, and A. T. Gray (Eds). Natural Products Isolation, 2nd Ed. Totowa, Humana Press.

[22] SEENIVASANRAO, REKHA. M, INDU, H, AND GEETHA S. 2012. Antibacterial activity and phytochemical analysis of selected seaweeds from Mandapam coast India. Journal of Applied Pharmaceutical Science 2 (10): 159-169.

[23] SERRANO J, PUUPPONEN-PIMIA R, DAUER A, AURA A, SAURA-CALIXTO F. 2009 Tannins: current knowledge of food sources, intake, bioavailability and biological effects. Molecular Nutrition Food Research, 53: S310 29.

[24] SUN, HONG-XIANG; XIE, YONG; YE, YI-PING (2009). "Advances in saponin-based adjuvants". Vaccine. 27 (12).

[25] TAPAS AR, SAKARKAR DM, KAKDE RB. 2008. Flavonoids as Nutraceuticals: A Review. Tropical Journal of Pharmaceutical Research, 7: 1089-1099.

[26] TREASE GE, EVANS WC. PHARMACOGNOSY. 2002. 15th Ed. London: Saunders Publishers; pp. 42- 44. 221-229, 246-249, 304-306, 331-332, 391-393.

[27] VARGHESE, J. G., A. A. KITTUR, P. S. RACHIPUDI and M. Y. KARIDURAGAN-AVAR. 2010. Synthesis, characterization and per Evaporation performance of chitosang- polyaniline membranes for the dehydration of isopropanol. Journal of Membrane Science 364 (1-2): 10.

[28] WINK M, SCHMELLER T, LATZ-BRIINING B. 1998. Modes of action of all chemical alkaloids: Interactions with neuroreceptors, DNA and other molecular targets. Journal of chemical Ecology, 24: 1888- 1937. 